\title{
An Experiment in Social Engineering in Serving the Families of Predelinquents ${ }^{1}$
}

\author{
Richard B. Stuart ${ }^{2}$ \\ Weight Watchers International \\ State University of New York, Stony Brook \\ Tony Tripodi \\ University of Michigan \\ Sirinika Jayaratne \\ Washington State University \\ Donald Camburn \\ Eastern Michigan University
}

One hundred and two predelinquent adolescents were randomly assigned to one of two conditions: an experimental condition in which behavioral contracting services were offered both at home and in school or a control condition in which clients were told that they could not be accommodated by project therapists and were informed about the possibility of their receiving treatment in other programs in the community. Most of those who were assigned to the control condition did not avail themselves of services in these other programs. Results indicate that, relative to the controls, the behaviorally treated youth scored small but 'statistically significant improvement relative to the controls on five measures: ratings of school behavior by the person who originally referred them for service, by their teachers, by their mothers, and by their fathers, and ratings of their parent-child interactions as measured by their mothers. Gains were also reported in mothers' ratings of their children's behavior at home. The failure of

Manuscript received in final form April 7, 1976.

${ }^{1}$ This study was supported by Grant R01-MH21452 from the Center for Studies of Crime and Delinquency, National Institute of Mental Health. The authors wish to thank L. Nilles, who served as general administrator of this project, and C. Faller, S. Iman, P. Ippel, L. Lott, J. Marsh, C. Stephenson, J. Tanter, D. Virtue, and R. Welter, who served as therapists.

${ }^{2}$ Requests for reprints should be sent to Richard B. Stuart, Weight Watchers International, 800 Community Drive, Manhasset, New York 11030. 
significant gains to be made in two measures of school performance - grades and attendance - is explained by the failure of the treatment techniques to overcome an age-related deterioration in these areas found among most children in the participating schools. The failure of fathers to find significant improvement in their relationships with the referred adolescents is viewed as a consequence of unanticipated changes in the intrafamilial balance of power resulting from contracting services. Finally, a subsidiary analysis showed that the contracting service appeared to offer the greatest gain to the demographically defined subgroups of youths who are among the population-at-risk in many juvenile courts.

Until recently there has been little reason for anyone involved in the treatment of predelinquent or "acting-out" youth to be optimistic about the results of the services provided. Whether predelinquents received institutionally based care (Bailey, 1966; Stuart, 1971b) or psychotherapy offered in community clinics (Levitt, 1971), most of them failed to improve as a result of the treatment, and many suffered deterioration. The rate of treatment failures is attributable to several factors. First, the treatment was often based upon an assessment of the "dispositional characteristics" (Stuart, 1971c) of the adolescent, rather than upon important manifest dimensions of his or her interaction with key people in the family and the community. Second, treatment recommendations more often tended to state mid- to long-term goals, rather than to specify precise methods for helping to promote the needed changes. Furthermore, the criteria for evaluating treatment tended to be global and therefore could not be used by therapists as a source of feedback about their work which would permit prompt adjustments in the clinical approach.

This pessimistic outlook has been changed recently by two important developments. First, social psychologists offered "social exchange theory" (E. G. Carson, 1969; Thibaut \& Kelley, 1959) as a means of describing and predicting the give-and-take of social interaction. And, second, family therapists (e.g., Haley, 1963; Minuchin, 1974) offered better means of describing and modifying family interaction. Armed with these tools, behavior therapists have been developing a battery of techniques that can be used to "reprogram the social environment" (Patterson, McNeal, Hawkins, \& Phelps, 1967) as a means of making lasting changes in the lives of adolescent clients. In pursuit of this goal, changes can be sought in both verbal and nonverbal communication patterns, the process of decision-making, and conflict-management techniques. Feedback, direct instigations, and training in negotiation are the methods commonly drawn upon to reach these goals in what has been essentially a directive (Frank, 1961) and action-oriented (London, 1964) approach.

One technique which is used extensively in this "operant-interpersonal" (Stuart, 1969; Stuart \& Lederer, in press) approach to treatment is "behavioral contracting" (Stuart, 1971a). This approach aims at helping develop negotiation 
skills needed for successful exchanges of adolescents, their parents, and their teachers. The therapist serves essentially as a mediator who: (1) creates an environment in which each person is free to express his or her desires, (2) offers a rationale for changing behavior so that each participant can make concessions without losing face, and (3) then provides a structure for carrying these negotiated changes into the natural environment of community living.

Three important gains are possible from this approach. First, each interacting pair of participants is helped to resolve a currently pressing conflict about who? is to do what? for whom? under what circumstances? Second, by temporarily setting aside focal conflicts, each individual has an opportunity to concentrate his or her energies upon improving social exchanges with others. Finally, each person is given the chance to acquire skill in bargaining which can be applied to other problems in the future.

When this technique is included in a comprehensive intervention package, important changes can be facilitated in the functioning of couples (e.g., Azrin, 1974) and families (e.g., Alexander \& Parsons, 1973; Patterson, 1974; Stuart, Jayaratne, \& Tripodi, in press). In this investigation, behavior contracting was used primarily in an effort to determine the amount of change which it can be expected to generate. Secondary goals of the research were efforts to determine whether contracting is more effective with some groups as opposed to others and to assess some of the intrafamilial changes resulting from professionally administered contracting services.

\section{METHOD}

\section{Subjects}

During the 1972-1973 and 1973-1974 academic years, school principals and counselors referred a total of 110 adolescents for counseling service. Of these, 8 were disqualified from treatment either because they were already receiving therapy elsewhere or because they anticipated imminent changes in their living situations (such as moving beyond the boundaries of the school district). The parents of the 102 remaining adolescents were informed that the Family and School Consultation Project was a federally funded program with limited capacity that would offer its services. All of the referred families were asked to complete baseline information and were told that they should, if untreated by the project, feel free to request service elsewhere. They were also instructed: (1) that the project staff would like to maintain contact with them, whether or not they were offered treatment, in order to learn about their experience over the ensuing 4 to 12 months and (2) that if they were not initially offered service, they could request treatment later. Families were then randomly 
assigned to either the experimental or the control conditions ${ }^{3}$ (Jayaratne, Stuart, \& Tripodi, 1974). After 4 months of treatment, eight control families availed themselves of the delayed treatment option.

The demographic characteristics of the samples yielded by randomly assigning subjects to experimental or control groups are summarized in Table I. On no measure did the difference between the groups reach the level of statistical significance. The groups were similar in race, sex, age, grade, parental age, the ordinal position of the referred adolescent, and family size. But the experimental group did have a modest overrepresentation of socially disorganized families. In the experimental group, $45.6 \%$ of the families were in the lowest income group, and $54.3 \%$ were single-parent families. In contrast, $28.9 \%$ of the control group families were in the lowest income category, and $35.6 \%$ were single-parent families. These demographic differences may favor a conservative bias in this comparison, a bias which is furthered by the fact that some of the control group families both sought and received outside services during the experimental period and were retained in the control group despite this fact.

\section{Procedures}

Referrals to the project were made on written forms and were accompanied with release-of-information forms signed by parents, permitting school personnel to discuss the youths' behavior at school with the research therapists. Following receipt of these materials, all families were seen for an initial datacollection session. At this time, the policies of the project were discussed. Families were notified by telephone within 3 days of their assignment to either the experimental or control group. If the family was assigned to the control group, the next therapeutic activity was discussion of each youth's status at school with the appropriate teachers and counselors.

\footnotetext{
${ }^{3}$ Given the recent controversy about the ethics of research with human subjects, the deception of this approach might not be employed now. However, six factors could be cited in support of the procedure used. First, it was reviewed and approved by an independent human subjects review committee. Second, the true objectives of the research were discussed with school administrators and all relevant personnel prior to the start of the project. Third, in contrast to common practice, control group families were not discouraged from seeking help elsewhere, approximately one-fifth having sought this help through school personnel alone. Fourth, the therapists were not aware of the condition to which the families had been assigned so that they were not dishonest during the initial interview. Fifth, it was believed that the deception was necessary to prevent the "Hawthorne effect" from positively biasing families assigned to the experimental condition so that deception was consistent with conservative research practice. Finally, by attributing the decision to treat or not to treat to the therapeutic capacity of the project, it was believed that no stigma would be associated with assignment to either the experimental or control conditions. Despite these caveats, however, the appropriateness of the procedure used here is debatable.
} 
Table 1. Demographic Characteristics of the Families Assigned to the Experimental and Control Groups

\begin{tabular}{|c|c|c|c|c|c|}
\hline & \multicolumn{2}{|c|}{ Experimental group } & \multicolumn{2}{|c|}{ Control group } & \\
\hline & Number & Percent & Number & Percent & \\
\hline Race & & & & & $\chi^{2}=.45145, d f=1$, n.s. \\
\hline White & 40 & 70.2 & 27 & 60.0 & \\
\hline Black & 17 & 29.8 & 18 & 40.0 & \\
\hline Sex & & & & & $x^{2}=.53684, d f=1$, n.s. \\
\hline Male & 41 & 71.9 & 27 & 60.0 & \\
\hline Female & 16 & 28.1 & 18 & 40.0 & \\
\hline Income & & & & & $\chi^{2}=.98408, d f=2$, n.s. \\
\hline$<\$ 9,000$ & 26 & 45.6 & 13 & 28.9 & \\
\hline$\$ 9,000<\$ 15,000$ & 14 & 24.6 & 17 & 37.8 & \\
\hline$\geqslant \$ 15,000$ & 17 & 29.8 & 15 & 33.3 & \\
\hline Age & & & & & $x^{2}=1.1615, d f=3$, n.s. \\
\hline$<13$ & 21 & 36.8 & 15 & 33.3 & \\
\hline $13<14$ & 19 & 33.3 & 14 & 31.1 & \\
\hline $14<15$ & 14 & 24.6 & 10 & 22.2 & \\
\hline $15+$ & 3 & 5.3 & 6 & 13.3 & \\
\hline Grade & & & & & $x^{2}=2.40838, d f=4$, n.s. \\
\hline 6 & 10 & 17.5 & 3 & 6.7 & \\
\hline 7 & 14 & 24.6 & 17 & 37.8 & \\
\hline 8 & 22 & 38.6 & 15 & 33.3 & \\
\hline 9 & 8 & 14.0 & 5 & 11.1 & \\
\hline 10 & 3 & 5.3 & 5 & 11.1 & \\
\hline Family composition & & & & & $\chi^{2}=6.9270, d f=3$, n.s. \\
\hline 2 natural parents & 14 & 24.1 & 22 & 48.9 & \\
\hline 1 parent & 31 & 54.3 & 16 & 35.6 & \\
\hline 1 step and 1 natural & 10 & 17.5 & 5 & 11.1 & \\
\hline Foster/adoptive & 2 & 3.5 & 2 & 4.4 & \\
\hline Father's age $a$ & & & & & $\chi^{2}=.013, d f=1$, n.s. \\
\hline$\leqslant 40$ & 25 & 55.6 & 19 & 54.3 & \\
\hline$\geqslant 41$ & 20 & 44.4 & 16 & 45.7 & \\
\hline Mother's age $b$ & & & & & $x^{2}=.768, d f=1$, n.s. \\
\hline$\leqslant 37$ & 28 & 51.9 & 18 & 40.9 & \\
\hline$\geqslant 38$ & 26 & 48.1 & 26 & 59.1 & \\
\hline $\begin{array}{l}\text { Sibling position } \\
\text { of client }\end{array}$ & & & & & $\chi^{2}=.286, d f=1$, n.s. \\
\hline Oldest or only & 21 & 36.8 & 14 & 31.1 & \\
\hline Nonoldest & 36 & 63.2 & 31 & 68.9 & \\
\hline Family size & & & & & $\chi^{2}=.242, d f=1$, n.s. \\
\hline $1-3$ children & 22 & 38.6 & 20 & 44.4 & \\
\hline $4-9$ children & 35 & 61.4 & 25 & 55.6 & \\
\hline
\end{tabular}

${ }^{a}$ Data were unavailable for 12 experimentals and 10 controls.

${ }^{b}$ Data were unavailable for 3 experimentals and 1 control. 
The procedures used in efforts to influence the students' behavior in school have been described elsewhere (Stuart, 1974). Briefly, they began with an assessment of the students' academic progress, and recommendations were made to increase the appropriateness of assignments in light of the students' interests and abilities. Teachers then filled out a Privilege Checklist which surveyed the teachers" willingness to utilize certain reinforcements (e.g., "A grade based upon own improvement rather than on class norm," "Permission to help other students...," or "Lunch outside of school with school personnel of his or her choice"). These reinforcements were then suggested as consequences for specific academic and social behavioral changes sought by the teacher. With the adolescents' participation, these reinforcements and goals were then formalized into behavioral contracts. Because it had been found earlier (Stuart \& Lott, 1972) that therapists tended to be somewhat idiosyncratic in their approach to contracting and because experimenter failure to follow the protocol has been cited as one of nine threats to the validity of experimental results (Barber, 1973), standardized contracts and contract instigation techniques were employed with both teachers and parents (Jayaratne et al., 1974). Moreover, teachers were asked to sign a contract with therapists which specified the responsibilities of both in efforts to improve the students' performance in school.

Contract revisions could be undertaken wherever they were needed. It was not unusual for three or four contracts to be negotiated in service for a single adolescent, with later contracts prescribing fading of the intensity of treatment through such transitions as replacing daily with weekly feedback cards or increases in the amount and/or quality of work required to obtain specified privileges.

Shortly after the first contact with the students' teachers, therapeutic contacts were initiated with families. These began with the discussion and signing of a treatment contract specifying: (1) the priorities assigned to school and home behavior, (2) responsibilities of the family such as keeping regularly scheduled appointments and honoring behavioral contracts, and (3) responsibilities of the therapist illustrated by a commitment to facilitate communication and cooperation between teachers and parents and to work toward the achievement of specified goals. The parents and adolescent then completed a Contracting Worksheet, which noted the privileges that each would like to enjoy (in terms of behaviors to be changed by the others) and the responsibilities that each was willing to meet in order to earn these privileges.

Contracts were initially aimed at enhancing school behavior, and reinforcements mediated at home were used to strengthen compliance with homework assignments and/or school attendance (Bailey, Wolf, \& Phillips, 1970). Subsequent contracts also included changes in home behavior. Sometimes contracts were revised because earlier versions proved ineffective. At these times, changes typically included either a reduction in the level of responsibilities and resulting privileges to simplify the contract, the introduction of new responsibili- 
ties which would alter deviance-producing situations (e.g., participation in community center activities rather than spending unstructured time on the streets), or the redesign of privileges or responsibilities to increase the likelihood that the recommendations would be followed. These last changes often involved making the changes less demanding and/or more objectively monitorable.

In contrast to the somewhat more demanding work done by Patterson (1974) which required an average of 60 hours of treatment time, the new techniques required an average of 20.57 hours. This time was divided as follows: an average of 11.26 hours of in-person contact with families $(S D=13.21$, range $1.30-21.49)$; an average of 1.08 hours of telephone contact with families $(S D=$ 41 , range $.12-2.55)$; an average of 8.16 hours of in-person contact with teachers $(S D=5.55$, range $.25-22.35)$ and an average of .07 hours of telephone contact with teachers ( $S D$ incalculable, range .00-1.55). The differences in treatment times resulted from an interaction of two factors: the service demands of individual cases and the tendencies of therapists to use different styles of interpersonal influence in seeking to gain clients' cooperation. Unfortunately, these service delivery differences introduce an uncontrolled source of bias in this approach, but prior study of these techniques (Stuart et al., in press) revealed that these differences were not systematically related to treatment outcome.

The shorter contacts tended to be characteristic of the more successfully treated families and, paradoxically, of families who refused to continue in project services after learning about treatment methods at the first treatment session. Longer contacts tended to reflect the greater amount of time used in efforts to help more troubled families. Irrespective of the duration of treatment contact, data from every family assigned to the experimental group are included in the results of that group.

\section{Measures}

Ten outcome measures were used in this research, with indices of home and school behavior having been previously shown to be clustered independently (Jayaratne et al., 1974). School behavior was measured by grades and percent of days absent per quarter and by evaluations of school behavior by teachers, referral agents, and both parents. Unfortunately, letter grades were not given to all sixth grade and some seventh grade students so that pre-post comparisons for some of our junior high school subjects were impossible. For those for whom these data were available, letter grades were converted to a 13-point numerical scale (A-plus $=13, A=12$, etc.) for the purpose of statistical analysis. Furthermore, because one of the participating junior high schools did not collect attendance data, these data were not available for some of the subjects.

The teacher and referral evaluation forms each consist of seven 5 -interval, Likert-type scales. The teacher evaluation form contains questions such as: 
"How much of his academic potential do you feel he is using? $0-20 \% \ldots$ 81-100\%" and "How often is he a behavior problem in your class? Almost never ... Daily." The referral evaluation form contains similar questions, adapted to the perspective of school counselors and assistant principals. Sample questions from this form are: "Approximately how often does a teacher or other staff members say something positive to you about him? Almost never ... Daily" and "How is he currently getting along with other students? Much better than the average student ... Much worse than average." The parental evaluations of school behavior, parent-child interaction, and home behavior all take similar form. The Likert-type scalar items in these scales include, respectively: "How satisfied are you with the rate of your child's class attendance? Very satisfied ... Dissatisfied," "How often does your child volunteer information about his activities and friends? Almost always ... Almost never," and "How satisfied are you with your child's keeping curfew? Very satisfied ... Dissatisfied."

None of the outcome measurements were made by therapists because of the likelihood of bias in therapists' assessment of their own work (Avnet, 1965). Therefore, assessments were made both by parents and by school personnel. Because the youths' behavior was defined as deviant by a consensus of teachers, assistant principals, and/or counselors, and by parents, the judgments rendered by these agents of social control were considered to be important criteria of the targeted changes in the adolescents' behavior. Efforts to collect direct observational data in classrooms were aborted when it was learned that, despite all efforts to conceal the identity of targeted students, the referred youths were consistently aware that they were the subjects of observers' attention. This awareness appeared to lead to positive changes in their behavior, invalidating observational data.

\section{RESULTS}

To control for differences in the pretreatment scores of subjects in the experimental and control groups, results were evaluated through analysis of covariance. The results of this analysis (see Table II) revealed that experimental subjects outperformed controls on eight out of ten measures. While many of the differences were small, five reached the level of statistical significance $(p<.05)$ with one narrowly missing this level $(p<.08)$. The control group subjects were marginally superior on fathers' assessments of parent - child interaction and on fathers' assessments of home behavior. Furthermore, experimental subjects demonstrated improvement in eight areas, deteriorating only in attendance and the aforementioned fathers' ratings of home performance. In contrast, subjects in the control group showed improvement on five measures and deteriorated on 
Table II. Analysis of Covariance of Treatment Outcomes for the Treatment and Control Groups

\begin{tabular}{|c|c|c|c|c|}
\hline \multirow[b]{2}{*}{ Variable } & \multirow[b]{2}{*}{ Dimension } & \multicolumn{2}{|c|}{ Treatment group } & \multirow[b]{2}{*}{$F$} \\
\hline & & Treatment & Control & \\
\hline Grades & $\begin{array}{l}\text { Number } \\
\text { Pretreatment mean } \\
\text { Change }\end{array}$ & $\begin{array}{l}29 \\
6.14 \\
+.59\end{array}$ & $\left.\begin{array}{c}21 \\
6.42 \\
-.51\end{array}\right\}$ & 1.81 \\
\hline Attendance & $\begin{array}{l}\text { Number } \\
\text { Pretreatment mean } \\
\text { Change }\end{array}$ & $\begin{aligned} & 50 \\
& 9.38 \\
&-1.06\end{aligned}$ & $\left.\begin{array}{c}41 \\
10.95 \\
-4.78\end{array}\right\}$ & 1.90 \\
\hline $\begin{array}{l}\text { Referral } \\
\text { evaluation }\end{array}$ & $\begin{array}{l}\text { Number } \\
\text { Pretreatment mean } \\
\text { Change }\end{array}$ & $\begin{array}{c}50 \\
14.72 \\
+3.56\end{array}$ & $\left.\begin{array}{c}40 \\
14.32 \\
-1.60\end{array}\right\}$ & $8.19^{a}$ \\
\hline $\begin{array}{l}\text { Teacher } \\
\text { evaluation }\end{array}$ & $\begin{array}{l}\text { Number } \\
\text { Pretreatment mean } \\
\text { Change }\end{array}$ & $\begin{array}{c}52 \\
12.74 \\
+3.30\end{array}$ & $\left.\begin{array}{c}40 \\
12.51 \\
+1.66\end{array}\right\}$ & $8.86^{a}$ \\
\hline $\begin{array}{l}\text { School } \\
\text { behavior: } \\
\text { father }\end{array}$ & $\begin{array}{l}\text { Number } \\
\text { Pretreatment mean } \\
\text { Change }\end{array}$ & $\begin{array}{c}22 \\
11.78 \\
+3.24\end{array}$ & $\left.\begin{array}{c}16 \\
12.74 \\
+.86\end{array}\right\}$ & $10.09^{a}$ \\
\hline $\begin{array}{l}\text { School } \\
\text { behavior: } \\
\text { mother }\end{array}$ & $\begin{array}{l}\text { Number } \\
\text { Pretreatment mean } \\
\text { Change }\end{array}$ & $\begin{array}{c}52 \\
12.31 \\
+2.87\end{array}$ & $\left.\begin{array}{c}37 \\
11.96 \\
+1.17\end{array}\right\}$ & $4.60^{b}$ \\
\hline $\begin{array}{l}\text { Parent-child } \\
\text { interaction: } \\
\text { father }\end{array}$ & $\begin{array}{l}\text { Number } \\
\text { Pretreatment mean } \\
\text { Change }\end{array}$ & $\begin{array}{c}22 \\
23.17 \\
+1.67\end{array}$ & $\left.\begin{array}{c}16 \\
27.50 \\
+2.31\end{array}\right\}$ & .55 \\
\hline $\begin{array}{l}\text { Parent-child } \\
\text { interaction: } \\
\text { mother }\end{array}$ & $\begin{array}{l}\text { Number } \\
\text { Pretreatment mean } \\
\text { Change }\end{array}$ & $\begin{array}{c}52 \\
24.21 \\
+2.70\end{array}$ & $\left.\begin{array}{c}36 \\
23.30 \\
-1.04\end{array}\right\}$ & $9.61^{a}$ \\
\hline $\begin{array}{l}\text { Home behavior: } \\
\text { father }\end{array}$ & $\begin{array}{l}\text { Number } \\
\text { Pretreatment mean } \\
\text { Change }\end{array}$ & $\begin{array}{c}22 \\
11.70 \\
-.12\end{array}$ & $\left.\begin{array}{c}17 \\
12.70 \\
-.01\end{array}\right\}$ & .17 \\
\hline $\begin{array}{l}\text { Home behavior: } \\
\text { mother }\end{array}$ & $\begin{array}{l}\text { Number } \\
\text { Pretreatment mean } \\
\text { Change }\end{array}$ & $\begin{array}{c}52 \\
12.84 \\
+1.82\end{array}$ & $\left.\begin{array}{c}37 \\
12.43 \\
+.78\end{array}\right\}$ & 3.01 \\
\hline
\end{tabular}

five others (grades, referral evaluation, and mothers' assessment of parent-child interaction, in addition to the two measures on which the experimental subjects also deteriorated).

In keeping with a suggestion by Shapiro (1966) that group means often obscure changes in individuals, some of which may be quite negative (Bergin, 1971), the percentages of experimental and control subjects who improved, made no change, or deteriorated were examined. For all measures combined and 


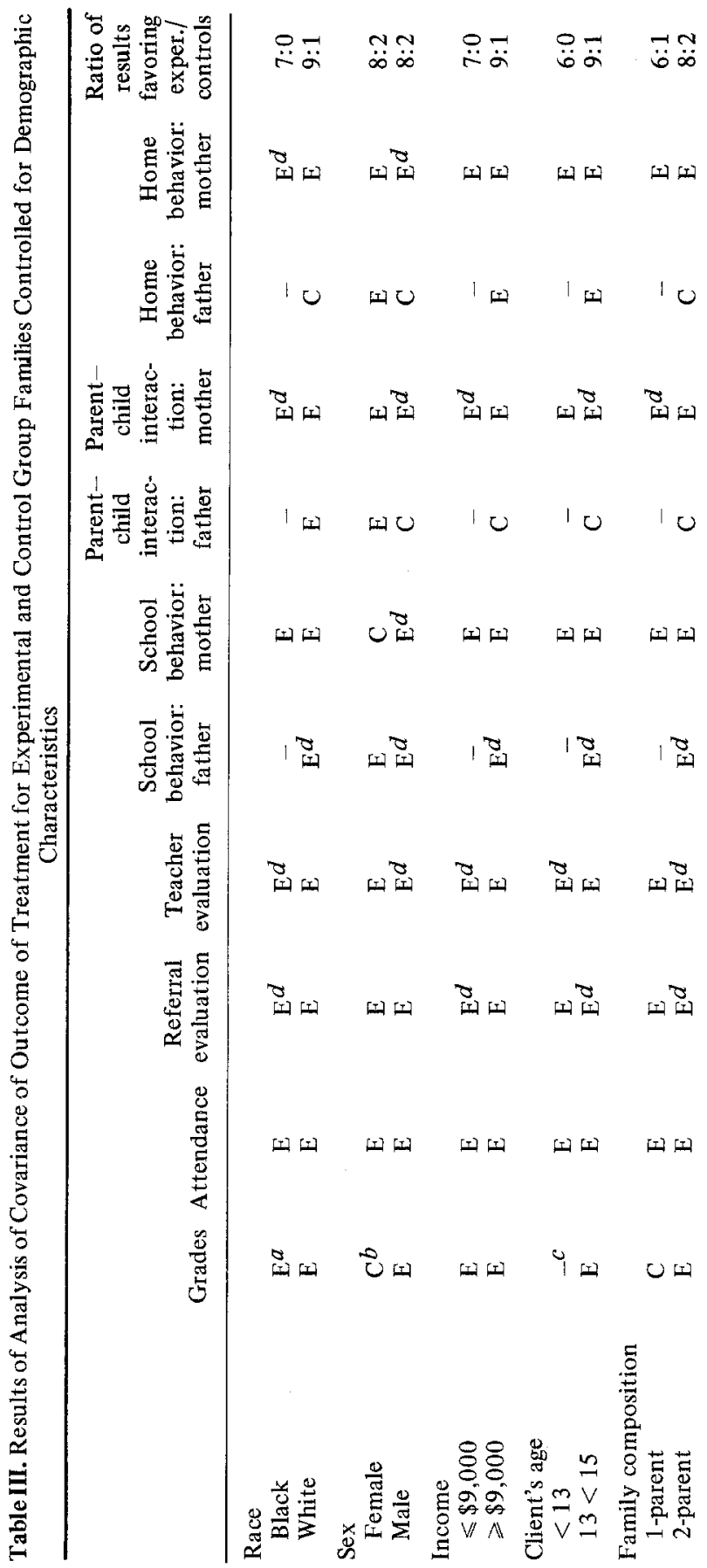




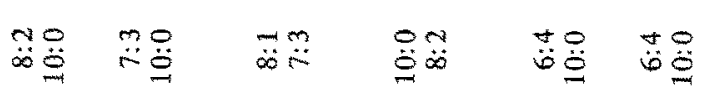

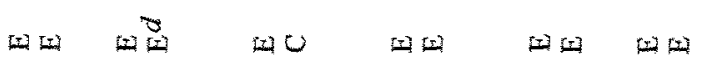

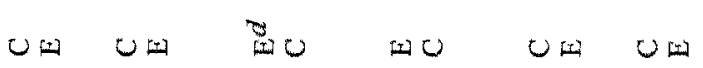

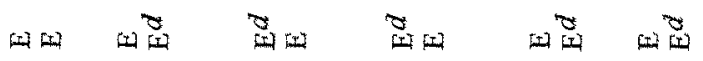
0 0 0 00 no

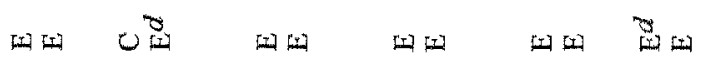

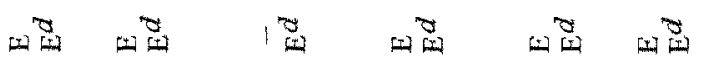

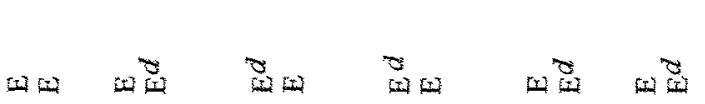

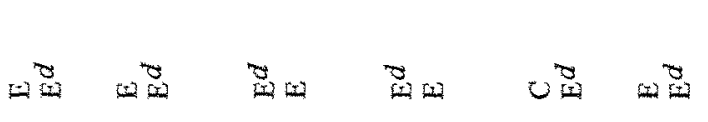

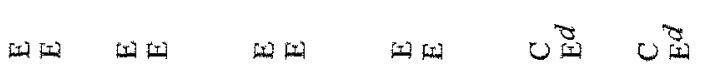

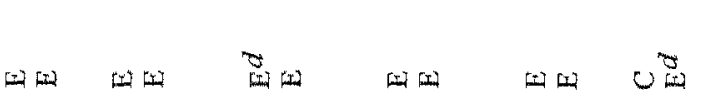

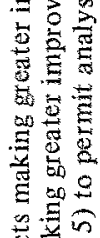

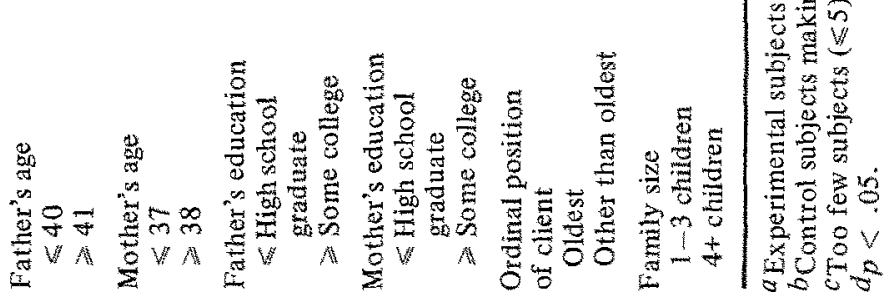


summing over all subjects in each experimental condition, this analysis yielded the following results:

$\begin{array}{lccc} & \text { Improved } & \text { No Change } & \text { Deteriorated } \\ \text { Experimental } & 64 \% & 28 \% & 8 \% \\ \text { Control } & 46 \% & 38 \% & 16 \%\end{array}$

A significant chi-square analysis of these results $(\bar{X}=7.41, d f=2, p<.05)$ suggests that experimental subjects were both more likely to improve and less likely to deteriorate than their counterparts in the control group.

The control group data contain two very interesting features. First, almost half of the controls showed improvement despite the fact that they were identified as posing relatively severe social adjustment problems in school and that most of them received almost no formal clinical service. This change may be ascribed to the "spontaneous" change of which Eysenck (1966) has written. Second, the behavioral deterioration rate among the controls was twice that of the experimental subjects. Taking these observations together, it may be concluded that while the experimental treatment did not offer the only available means of improvement, participation in this service did appear to reduce the likelihood that the adolescent's behavior would deteriorate during the passage of time which was otherwise devoted to treatment.

Two further analyses concerned the role of the relationship between the clients' demographic characteristics and their response to treatment. First, factors such as race, age of family members, and parents' education showed no effect on the outcome of service within the treatment group. Only 4 out of 90 evaluations (10 outcome measures by 9 demographic characteristics) were of statistical significance. Clients' demographic characteristics did, however, have a bearing upon the outcome of treatment between the experimental and control groups, as seen in Table III. Sample sizes permitted a total of 206 separate analyses (22 different demographic breakdowns for 10 variables, of which 14 comparisons had five or fewer subjects in a cell). Of these comparisons, $85.9 \%$ (177) favored the experimental subjects, while $14.1 \%$ (29) favored the controls. Of the results favoring the experimentals, $31.3 \%$ (55) reached the level of statistical significance; of those favoring controls, $3.5 \%$ (1) reached this level. Therefore, it is clear that when demographic characteristics are held constant, strong differences between experimental and control group outcomes result. For eight of the subgroups (blacks, 10-12-year-olds, low-income families, those with fathers 41 and older, those with mothers 38 and older, families with mothers having high school education or less, clients who were not the eldest children in their families, and families with four or more children), all of the comparisons favored the experimental subjects. Seven of the differences were statistically significant for the families with older mothers; six reached this level for larger families and for clients who were not the oldest child; and five reached this level 
in comparisons involving males and with families in which fathers had high school or less education.

\section{DISCUSSION}

Two factors should be borne in mind in interpreting the results of this research. First, the intervention depended primarily upon use of a single technique, while naturally occurring service programs typically utilize a number of techniques. Second, the research and statistical procedures were planned to minimize Type 1 error.

One of the disappointments of this research is its failure to demonstrate significant changes in the academic performance of its subjects. Although experimental subjects did make a slight improvement in grades, this difference was not statistically significant relative to the decline of grades recorded for the controls. Moreover, both groups recorded a lower percentage of days of school attended after treatment when contrasted with pretreatment attendance. It is of interest, however, that these negative results on the "hard" measures of outcome are inconsistent with improvement in the "soft" measures of adult ratings of the clients' school behavior.

Gold and Mann (1972) have shown that grades received in school have a profound impact upon student's self-assessment and, in turn, upon their delinquent status. Therefore improvement in grades would seem to be a very important objective of treatment services. Nevertheless, researchers have continually found that neither grades nor attendance are reactive to treatment (Fo \& O'Donnell, 1974; Love, Kaswan, \& Bugenthal, 1972; Reckless \& Dinitz, 1972; Sarri \& Vinter, 1969). There are at least two possible explanations for the failure of the present research to produce positive changes in these critical measures.

The first possible explanation is an apparent breakdown in the technology. When home reinforcements were used to strengthen school behaviors, teachers were asked to rate the students' daily behavior on class cards. Parents then granted or withheld privileges on the basis of these reports. Accurate information by teachers permitted parents to grant access to privileges on a responsecontingent basis, while teacher reports which were falsely positive led parents to positively reinforce, at home, neutral or negative behavior at school. Unfortunately, teachers sometimes tended to give this false positive feedback in order to avoid daily confrontation by the student. This was misleading to both parents and therapists. Therefore, it was not-surprising to learn that the correlation between report card grades and daily reports was a disappointing 25 (Jayaratne et al., 1974). Any replication of this research would, therefore, have to build in methods of securing teacher cooperation which were more powerful than those used here. For example, teachers might be provided with summaries of their daily ratings at the end of each marking period for review prior to assigning term 

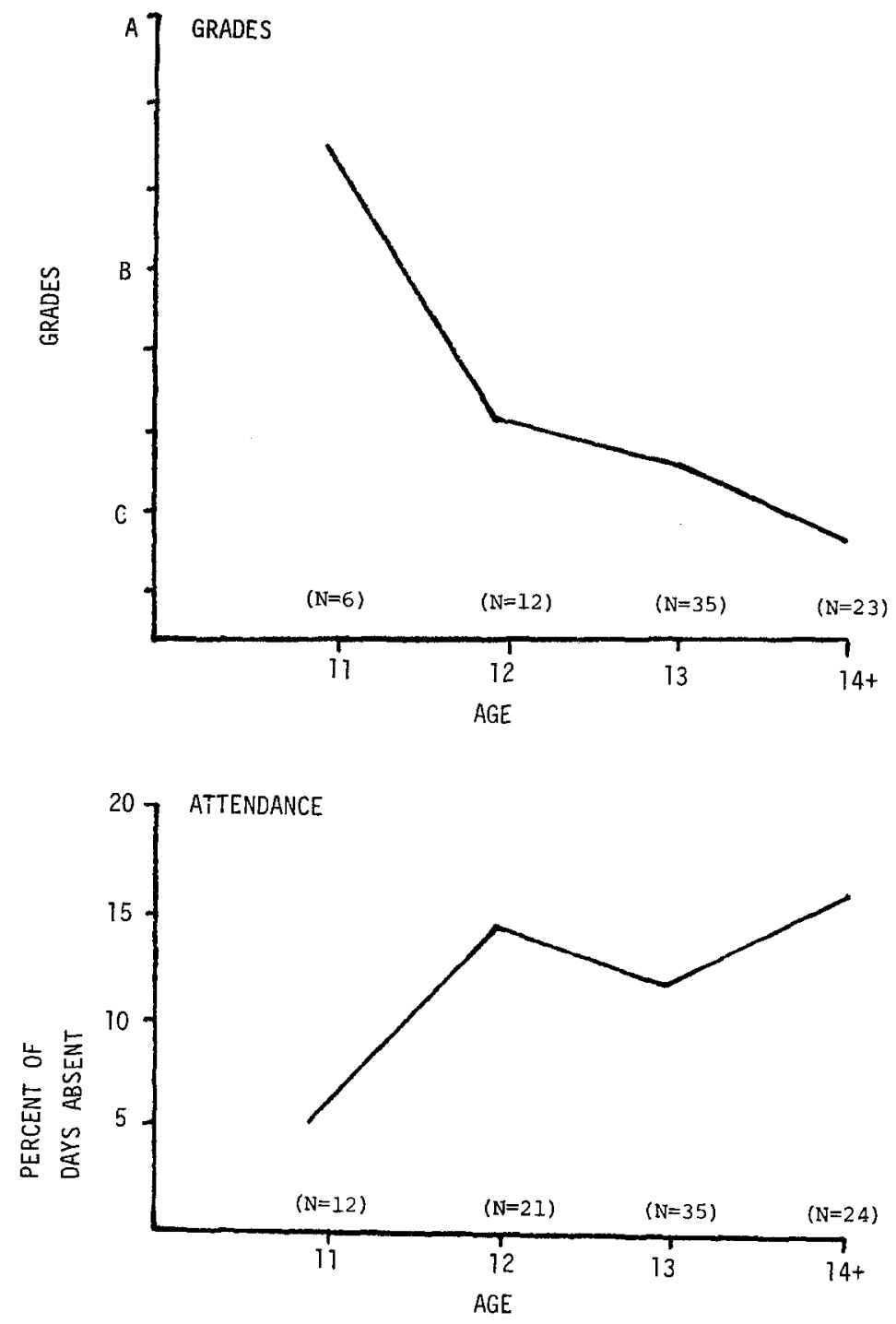

Fig. 1. Age trends in the grades and attendance of all subjects.

grades. Also, teachers could be offered training in how to give students negative information in the most positive manner possible.

A second explanation for the failure of grades and attendance to show a positive reactivity to treatment may be found in a very generalized trend of teachers giving students lower grades in each year of their schooling. Data presented in Figure 1 reflect a satistically significant $(F=5.95, d f=75$, $p<.0001)$ trend toward lower grades for older students and a nonlinear and, 
hence, statistically nonsignificant $(F=1.18, d f=91$, n.s.) trend toward higher absence rates. It is possible that work assignments in junior high school are cumulative, with assignments in later years building upon skills developed earlier. Therefore, if deviant youngsters do poorly early in junior high school, they may be doomed to fail later. However, it is also possible that students receive progressively lower grades because of a labeling effect (Schafer \& Polk, 1967), and this , rather than actual ability, might set a decreasing ceiling upon evaluations of the student. If this were the case, it would not be surprising that older students who receive reduced reinforcement for school attendance in the form of grades might, therefore, attend school less. This association between accurate feedback, grades, attendance, and age is of sufficient importance to be the object of further study among both deviant and nondeviant youth.

Turning now to the second area in which the results were poorer than expected, it will be recalled that, while mothers reported significant levels of improvement in the adolescents' home and school behavior, fathers reported positive school changes but mildly negative changes at home. One explanation of this outcome was sought in fathers' assessments of the adequacy of the treatment which the youth received. Reactions to treatment were determined at the time of posttreatment data collection by asking five questions (e.g., "How helpful do you feel your contact with the Family and School Consultation Project has been?') which were scored on our standard 5 -interval Likert-type scale. Low scores on this scale reflect positive ratings. The results of this assessment indicated that fathers were the most pleased with treatment $(\bar{X}=7.00, S D=1.72)$, followed by their wives $(\bar{X}=7.55, S D=2.30)$ and lastly by their adolescent children $(\bar{X}=11.19, S D=3.98)$. The fact that fathers were more satisfied with treatment than their wives $(t=1.96, d f=69$, n.s.), while both rated the service as more beneficial than did their children $([t=5.74, d f=65, p<.001]$ for fathers-adolescents and $[t=7.97, d f=89, p<.001]$ for mothers-adolescents), eliminates treatment dissatisfaction among fathers and the "halo" effect among mothers as possible explanations.

Another explanation for the differential responses of fathers and mothers was sought in an examination of the changes which took place within families as treatment progressed. This line of reasoning was suggested by recent research which has pointed out an association between communicational patterns, power dimensions of parent-child interaction, and adolescents' conformity to or apparent rejection of standards of prosocial behavior (e.g., McPherson, 1974; McPherson, Goldstein, \& Rodnick, 1973). In this vein, adolescents and their parents were asked to express their views of how parents allocate responsibility for decision-making concerning four aspects of the adolescent's school-related behavior (class attendance, academic performance at school, social behavior at school, and the completion of homework assignments) and four aspects of home-related behaviors (completion of chores, acceptable behavior at home, keeping of curfew, and personal appearance). Each of these areas was rated on a 5-point Likert-type scale with " 1 " indicating that fathers always made the 
decisions, " 3 " that the parents decided equally, and " 5 " that mothers had all of the decision-making authority. The summed rating scores for school behavior and for home behavior yielded a possible range from 4 to. 20, with lower scores indicating an increase in father power and higher scores indicating an increase in the power of mothers.

Figure 2 summarizes the changes which were recorded in these measures from the start to the end of treatment. It can be seen that: (1) adolescents believed that their mothers gained authority with respect to both school and home behaviors; (2) mothers believed that they yielded authority in both areas to their husbands; (3) fathers believed they slightly increased their level of authority with respect to their child's school and home behavior. Given the shared limitations of these data - that they were available for only 20 of the 26 two-parent families and that they are rather global and impressionistic ratings they nevertheless do suggest a possible explanation for the failure of fathers to rate their relationships with their youngsters as significantly improved. Following treatment, fathers and mothers both believed that the fathers gained in authority in home behavior. The adolescents, on the other hand, perceived an increase in their mothers' influence. Therefore, at the same time that fathers may have expected to exert more control, their children may have turned more to their mothers for direction. If the fathers felt frustrated by the contrast between their expected increased influence and their realized decrease in influence, this negative reaction may have colored their evaluation of changes in their children's behavior at home.

This is a highly speculative series of inferences which go beyond the scope of the data in this research. They do, however, call attention to the fact that unexpected changes may occur within the families which receive behavior therapy as a consequence of the way in which the services are delivered and/or the specific details of the services themselves. Future investigators should be sensitive to this potentially important influence upon the outcome of services.

Finally, it is of interest to contrast the findings in this research concerning the impact of services upon demographically defined subgroups of clients with those of other investigators. In this research, evidence supports the conclusion that the clinical procedures appear to be most effective with the populations-atrisk in most juvenile court settings: those who are black, have older and less well-educated parents, have larger families, and have lower incomes. Love et al. (1972) found similar results for their directive and advice-giving procedures. In contrast, Patterson (1974) found that middle-class parents responded better to his treatment, which was more cognitively oriented because of its inclusion of responses to a written programmed instructional manual. Like Patterson, Love, et al. also found that when techniques were focused upon enhancing family's problem-solving abilities, middle-class families appeared to profit more. Therefore in addition to considering some of the often overlooked intrafamilial consequences of receiving behavior therapy, program planners would also be well 


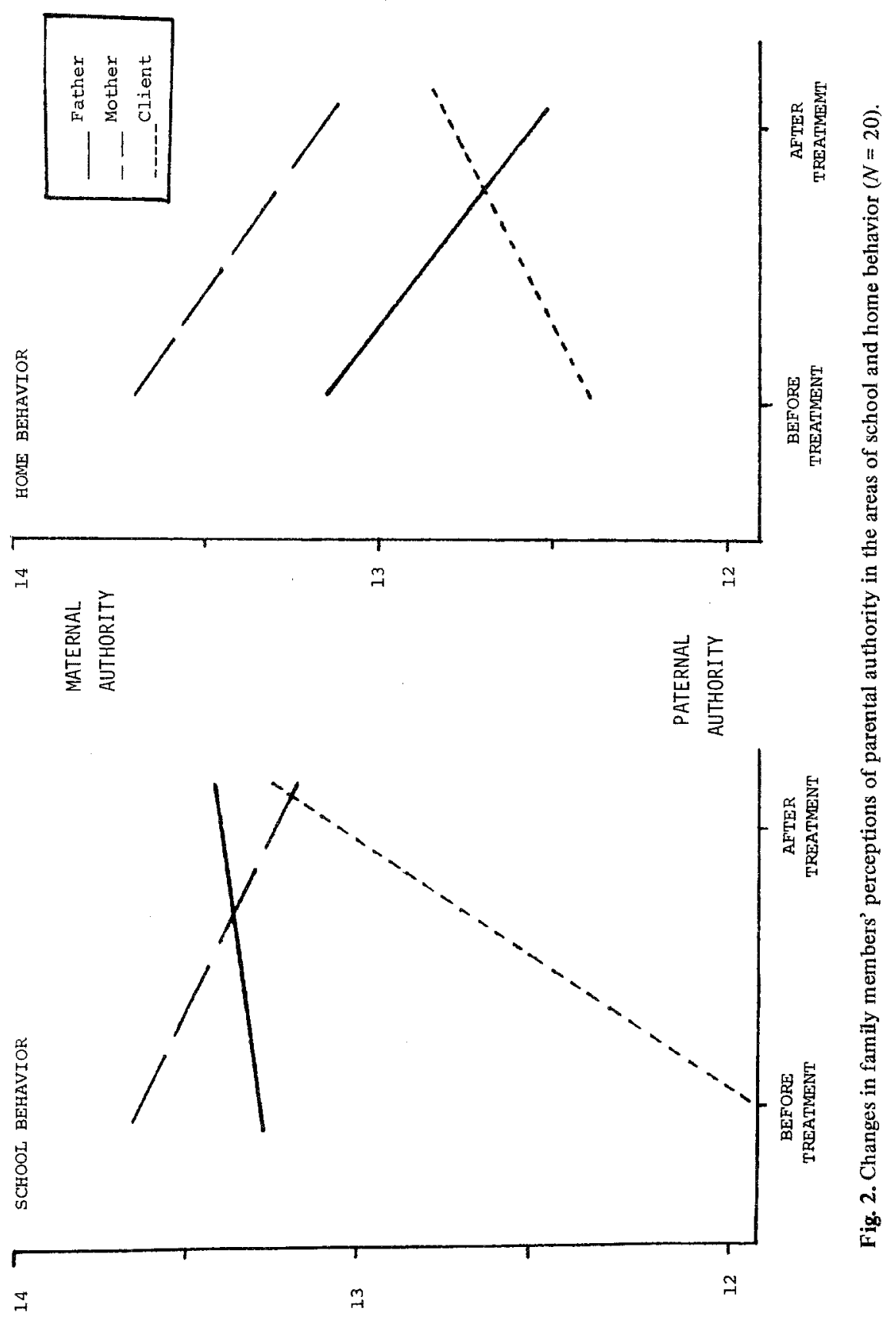


advised to anticipate the differential effectiveness of their methods with various subgroups of their clients.

In conclusion, it must be said that the results of this research clearly indicate that the single technique of behavioral contracting is no panacea. Contracting led to possible changes in the "softer" measures, while the "harder" measures of grades and attendance were comparatively unresponsive to intervention. Nevertheless, secondary analyses have suggested ways in which the contracting procedures can be strengthened by enhancing teacher compliance and by anticipating and perhaps redirecting changes in decision-making patterns within the family. When these adjustments are made and the contracting is made part of a more comprehensive intervention package that includes techniques aimed at modifying communication patterns within the family, academic skillbuilding at school, and improving peer experiences for the adolescent, it is expected that services for deviant youths will be greatly improved.

\section{REFERENCES}

Alexander, J. F., \& Parsons, B. V. Short-term behavioral intervention with delinquent families: Impact on family process and recidivism. Journal of Abnormal Psychology, $1973,81,219-225$.

Avnet, H. H. How effective is short-term psychotherapy. New York: Grune \& Stratton, 1965.

Azrin, N. H., Naster, B. J., \& Jonès, R. Reciprocity counseling: A rapid learning based procedure for marital counseling. Behavior Research and Therapy, 1973, 365-382.

Bailey, W. C. Correctional outcome: An evaluation of 100 reports. Journal of Criminal Law, Criminology and Police Science, 1966, 57, 153-160.

Barber, T. X. Pitfalls in research: Nine investigator and experimenter effects. In R. M. W. Travers (Ed.), Second handbook of research on teaching. Chicago: Rand McNally, 1973.

Bergin, A. E. The evaluation of therapeutic outcomes. In A. E. Bergin \& S. L. Garfield (Eds.), Handbook of psychotherapy and behavior change: An empirical analysis. New York: Wiley, 1971.

Carson, R. C. Interaction concepts of personality. Chicago: Aldine, 1969.

Eysenck, H. J. The effects of psychotherapy. New York: International Science Press, 1966.

Fo, W. S. O., \& O'Donnell, C. R. Relationship and contigency conditions in a community intervention program for youth with non-professionals as behavior change agents. Journal of Consulting and Clinical Psychology, 1974, 42, 163-169.

Frank, J. D. Persuasion and healing. New York: Schocken Books, 1961.

Gold, M., \& Mann, D. Delinquency as defense. American Journal of Orthopsychiatry, 1972, $42,463-479$.

Haley, J. Strategies of psychotherapy. New York: Grune \& Stratton, 1963.

Jayaratne, S., Stuart, R. B., \& Tripodi, T. Methodological issues and problems in evaluating treatment outcomes in the Family and School Consultation Project, 1970-1973. In P. O. Davidson, F. W. Clark, \& L. A. Hamerlynck (Eds.), Evaluation of behavioral programs in community residential and school settings. Champaign, Illinois: Research Press, 1974. 
Levitt, E. E. Research on psychotherapy with children. In A. E. Bergin \& S. L. Garfield (Eds.), Handbook of psychotherapy and behavior change: An empirical analysis. New York: Wiley, 1971.

London, P. The modes and morals of psychotherapy. New York: Holt, 1964.

Love, L. R., Kaswan, J., \& Bugenthal, D. E. Differential effectiveness of three clinical interventions for different socioeconomic groupings. Journal of Consulting and Clinical Psychology, 1972, 39, 347-360.

McPherson, S. R. Parental interactions at various levels. Journal of Nervous and Mental Diseases, $1974,158,424-431$.

McPherson, S. R., Goldstein, M. J., \& Rodnick, E. H. Who listens? Who communicates? How? Archives of General Psychiatry, 1973, 28, 393-401.

Minuchin, S. Families and family therapy. Cambridge: Cambridge University Press, 1974.

Patterson, G. R. Interventions for boys with conduct problems: Multiple settings, treatments and criteria. Journal of Consulting and Clinical Psychology, 1974, 42, $471-481$.

Patterson, G. R., McNeal, S., Hawkins, N., \& Phelps, R. Reprogramming the social environment. Journal of Child Psychology and Psychiatry, 1967, 8, 181-195.

Reckless, W. C., \& Dinitz, S. The prevention of juvenile delinquency: An experiment. Columbus: Ohio State University Press, 1972.

Sarri, R. C., \& Vinter, R. D. Group work for the control of behavior problems in secondary schools. In D. Street (Ed.), Innovation in mass education. New York: Wiley, 1969.

Schafer, W. D., \& Polk, K. Delinquency and the schools. In Task Force on Juvenile Delinquency, The President's Commission on Law Enforcement and Administration of Justice. Juvenile delinquency and youth crime. Washington, D. C.: U. S. Government Printing Office, 1967.

Shapiro, M. The single case in clinical-psychological research. Journal of General Psychology, 1966, 74, 3-23.

Stuart, R. B. Operant interpersonal treatment of marital discord. Journal of Consulting and Clinical Psychology, 1969, 33, 576-582.

Stuart, R. B. Behavioral contracting with the families of delinquents. Journal of Behavior Therapy and Experimental Psychiatry, 1971,2, 1-11. (a)

Stuart, R. B. Behavioral control of delinquency: Critique of existing programs and recommendations for innovative programs. In L. A. Hamerlynck, F. Clark, \& L. Acker (Eds.), Innovative services to youth. Calgary: University of Calgary Press, 1971.(b)

Stuart, R. B. Trick or treatment. Champaign, 1linois: Research Press, 1971.(c)

Stuart, R. B. Behavior modification for the educational technologist. In R. Ulrich, T. E. Stachnik, \& J. Mabry (Eds.), Control of human behavior (Vol. 3). New York: Scott Foresman, 1974.

Stuart, R. B., Jayaratne, S., \& Tripodi, T. Changing adolescent deviant behavior through reprogramming the behavior of parents and teachers: An- experimental approach. Canadian Journal of Behavioral Science, in press.

Stuart, R. B., \& Lederer, W. J. How to make a bad marriage good and a good marriage better. New York: W. W. Norton, in press.

Stuart, R. B., \& Lott, L. A., Jr. Behavioral contracting with delinquents: A cautionary note. Journal of Behavior Therapy and Experimental Psychiatry, 1972, 3, 161-169.

Thibaut, J. W., \& Kelley, H. H. The social psycholgoy of groups. New York: Wiley, 1959. 